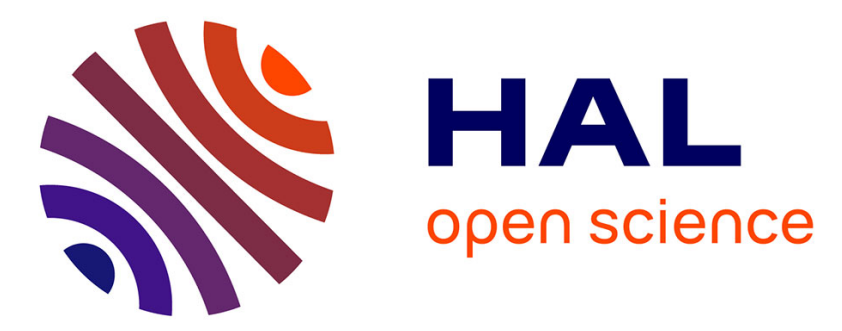

\title{
The Valence Bond Workshop in Paris: The Phoenix Rises from the Ashes or, Has a Love Story with MO-Based Theories Begun?
}

Benoît Braïda, Etienne Derat, Stéphane Humbel, Philippe C. Hiberty, Sason Shaik

\section{To cite this version:}

Benoît Braïda, Etienne Derat, Stéphane Humbel, Philippe C. Hiberty, Sason Shaik. The Valence Bond Workshop in Paris: The Phoenix Rises from the Ashes or, Has a Love Story with MO-Based Theories Begun?. ChemPhysChem, 2012, 13 (18), pp.4029-4030. 10.1002/cphc.201200784 . hal-01627702

\section{HAL Id: hal-01627702 https://hal.science/hal-01627702}

Submitted on 10 Nov 2017

HAL is a multi-disciplinary open access archive for the deposit and dissemination of scientific research documents, whether they are published or not. The documents may come from teaching and research institutions in France or abroad, or from public or private research centers.
L'archive ouverte pluridisciplinaire $\mathbf{H A L}$, est destinée au dépôt et à la diffusion de documents scientifiques de niveau recherche, publiés ou non, émanant des établissements d'enseignement et de recherche français ou étrangers, des laboratoires publics ou privés. 


\title{
The Valence Bond Workshop in Paris: The Phoenix Rises from the Ashes or, Has a Love Story with MO-Based Theories Begun?
}

\author{
Benoît Braïda, ${ }^{*[a]}$ Etienne Derat, ${ }^{*[b]}$ Stéphane Humbel, ${ }^{[c]}$ Philippe C. Hiberty, ${ }^{[\mathrm{d}]}$ and \\ Sason Shaik ${ }^{[\mathrm{e}]}$
}

During the week of July 17-23, 2012, the UPMC (Université Pierre et Marie Curie, Paris 06) hosted an international Workshop on valence bond (VB) theory, which was funded by the Paris-area node of the Centre Européen de Calcul Atomique et Moléculaire (CFCAM-IdF). The workshop has attracted a more than 80 participants, among them quite a few leading quantum chemists and computational chemists. On the face of it, this looks like a normal scientific event that needs no reporting. However, considering the state of VB theory for the past five to six decades, the large crowd of participants that was drawn despite the state of VB in chemistry, and the fantastic scientific atmosphere of the workshop that unified all participants, the workshop constitutes a truly historic event. Let us start with a short background that may underscore the potential meaning of this event to chemistry.

The new quantum mechanics of Heisenberg and Schrödinger provided chemistry with two general theories, one called VB theory and the other molecular orbital (MO) theory. The two theories were developed at about the same time, but have quickly diverged into rival schools that have competed, sometimes destructively, on charting the mental map and episte-

\footnotetext{
[a] Dr. B. Braïda

Benoit Braïda

UPMC Université Paris 06, CNRS UMR 7616

Laboratoire de Chimie Théorique

Case Courrier 137, 4 Place Jussieu

75252 Paris CEDEX (France)

E-mail: benoit.braida@upmc.fr

[b] Dr. E. Derat

Etienne Derat

UPMC Université Paris 06, CNRS UMR 7201

Institut Parisien de Chimie Moléculaire

4 place Jussieu, 75005 Paris (France)

E-mail:etienne.derat@upmc.fr

[c] Prof. S. Humbel

Stéphane Humbel

Aix Marseille Université, CNRS, iSm2 UMR 7313

13397 Marseille (France)

[d] Dr. P. C. Hiberty

Philippe Hiberty

Laboratoire de Chimie Physique

Bât 490, Université de Paris-Sud

CNRS UMR 8000, 91405 Orsay (France)

[e] Prof. S. Shaik

Sason Shaik

Institute of Chemistry and Lise Meitner-Minerva Center

for Computational Quantum Chemistry

The Hebrew University of Jerusalem

91904, Jerusalem (Israel)
}

mology of chemistry. In brief, until the mid 1950s VB theory had dominated chemistry, and then MO theory took over while VB theory fell into disrepute and was almost completely abandoned. The development of user-friendly MO-based and density functional theoretic (DFT) software, coupled with the lack of similar VB software, seemed to have put the last nail in the coffin of VB theory and substantiated MO theory as the only legitimate chemical theory, while VB has been branded, by some mysterious consensus, as an obsolete theory, or simply a wrong one. Nevertheless, despite this seemingly final judgment and the obituaries showered on VB theory in textbooks and in the public chemical opinion, this beautiful theory never really died. It has continued to live in the mental map of chemists, and to be used and developed by a handful of practitioners. Indeed, what has transpired in Paris was like a phoenix rising from the ashes.

However, something much more important emerged during the workshop: the participants, which came from different schools of quantum chemistry, witnessed a rare consensus that, irrespective of the computational tools, a fruitful way to understand chemistry is via local theories, be these strict VB, or a variety of ways for transforming delocalized-canonical methods, based on DFT, MO, or highly correlated wave function theory, to new pictures that lead to local information equivalent to VB. So, in another way, the workshop may even have marked a beginning of a love affair between VB and MO-based approaches to chemistry. ${ }^{[1]}$

The workshop involved plenary lectures by invited speakers as well as participants' talks. The afternoons were devoted to free discussions and practical know-how sessions where the participants were guided to complete a set of paper exercises and to perform practical VB calculations on the cluster of one of the organizers (E. Derat), using either the Xiamen Valence Bond (XMVB) program of $\mathrm{W}$. $\mathrm{Wu}^{[2]}$ or the block-localized wavefunction (BLW) program of Y. Mo. ${ }^{[3]}$

The workshop started with two lectures by P. C. Hiberty. The first lecture was aimed at teaching qualitative VB theory, showing how to write a VB wave function, and expressing the elementary interactions, bonding energies and matrix elements in terms of overlap integrals and ß-reduced resonance integrals just as with Hückel's MO theory. The second lecture was an overview of current ab initio VB methods, classified into two great families: those dealing with fully localized atomic orbitals and those using semi-localized orbitals. The generalized valence bond (GVB) method of Goddard and the spin-coupled method of Gerratt were briefly presented, as well as the 
breathing orbital VB method and other methods to include dynamic electron correlation, such as Valence Bond Configuration Interaction $(\mathrm{VBCl})$, Valence Bond second-order Perturbation Theory (VBPT2) and so on. In the third lecture, W. Wu described these latter methods in detail, as well as all solvation methods available with these ab initio VB methods. P. Su followed with a practical guide, which prepared the participants to perform their own VB calculations using the XMVB program.

The fifth lecture, by J.-P. Malrieu, established a bridge between VB and MO-based methods by showing how to perform a $V B$ reading of complete active space self-consistent field (CASSCF) and post-CASSCF wavefunctions, with special emphasis on the work of dynamic electron correlation. S. Shaik followed with the sixth and seventh lectures, which dealt with applications of VB theory to chemistry and biochemistry, using models called "VB state correlation diagrams" and "VB configuration mixing diagrams". He showed how these models apply to many reactions among which are, cycloadditions, $\mathrm{S}_{\mathrm{N}} 2$ reactions, hydrogen transfer reactions, and key oxidative reactions of the enzyme cytochrome P450. The eighth lecture was given by $\mathrm{Y}$. Mo on the block-localized wavefunction (BLW) method. He described the method and showed chemical applications, namely how to extract resonance energies and interaction energies from $\mathrm{MO}$ and DFT calculations, thus creating a bridge between MO/DF and VB theories. In the ninth lecture $C$. Landis reported another bridge between VB- and MO-based methods, using the natural bond orbital (NBO) analysis that provides a $\mathrm{VB}$ reading of any $\mathrm{MO}$ wave function or DFT density. Landis made many MO-VB connections, for example, to Shaik's talk by showing how the NBO and VB descriptions of the iron-oxo bond (in the active species of $\mathrm{P} 450$ ) are virtually identical.

The tenth lecture, by D. L. Cooper, described the spin-coupled VB method that deals with semi-localized orbitals, and the CASVB method which allows extracting the spin-coupled VB wave functions from a fast CASSCF calculation. Then, K. Boguslawski presented recent developments in the laboratory of Markus Reiher in wavefunction methods, including the density matrix renormalization group, and expressed her view that it may bridge to VB descriptors. Finally, the last plenary lecture was given by $\mathrm{G}$. Scuseria. It dealt with a potential connection between projected broken-symmetry Hartree-Fock wavefunctions (and beyond) and VB theory.

In addition to the plenary lectures there were shorter lectures of various aspects of VB theory and VB modelling, by M. Piris, T. Ziegler, P. Karafiloglou, R. Ramozzi, C. Parish, J. Gao, C. Angeli, J. T. Muya, C. Lepetit, J. M. Oliva, Z. Rashid, A. Tchougreeff, A. Shurki, S. De Visser, and L. Kamerlin. Some of the lecturers, for example, R. Ramozzi, J. Gao, A. Shurki, S. De Visser and L. Kamerlin, described VB modelling or applications on a large variety of chemical/biochemical problems. Other talks showed that a clear way of comprehending the results of $\mathrm{MO}$ / DFT-based calculations is by using a local approach. For example, M. Piris has used his method of generating localized orbitals from reduced density matrix calculations to show the solution of bonding puzzles. T. Ziegler has shown that interactions in large molecules can be understood in terms of his recently developed local descriptors based on diagonalization of the deformation density. J. Gao has shown that the BLW method can be used to generate VB type diagrams for reactivity. P. Karafiloglou talked about his method of reading VB information from any wave function. $C$. Angeli described VB reading of CASSCF wave functions for excited states. A. Tchougreeff gave a fascinating talk about the history of VB theory in Russia. The complete set of lectures, which can be downloaded, can be found at: http://wiki.lct.jussieu.fr/workshop/index.php/Program_of_the_VB_workshop

Three-hour tutorials (and sometimes more, due to the enthusiasm of the attendees) were organized every day in the late afternoon (prepared and tutored by: D. Danovich, A. Shurki, S. Humbel, M. Linares, P. Su, X. Chen, J. Song and F. Ying). The first tutorial dealt with paper exercises on hybridization and basic VB calculations using the XMVB program. The second tutorial dealt with qualitative and computational VB applications to $\pi$ systems, such as the allyl radical, ozone, benzene and the allyl cation. The third tutorial presented paper exercises and computational exercises on VB state correlation diagrams, with applications to $S_{N} 2$ reactions, hydrogen abstraction reactions and conical intersection in the $\mathrm{H}_{3}{ }^{\cdot}$ radical. The last tutorial proposed some applications of the BLW method of Y. Mo, and of the HuLis program, a Hückel-base VB code by $S$. Humbel. ${ }^{[4]}$ All the tutorial exercises and their answers can be found at: http://wiki.lct.jussieu.fr/workshop/index.php/VB_tutorial

The tutorials were also the focus of many fruitful discussions, which ended up as future projects and collaborations. All participants were enthusiastic about the workshop, and we received positive feedback from many of them. Owing to the availability of the XMVB or BLW programs and the tutorial sessions that enabled the participants to run their own VB calculations, it is hoped that VB theory will be given a new impetus and that many computational VB applications may follow and appear in the literature in the future. Only time will tell if this hope will indeed materialize. However, irrespective of these prospects, the main message of the workshop is that VB- and MO-based approaches to chemistry constitute a (re)unified thought culture of chemistry. There is no chasm between these approaches!

Considering the success of this first Valence Bond Workshop, ${ }^{[5]}$ we expect to organize such events on a regular basis in the future, which will hopefully tighten the MO-VB bond and attract further newcomers to the VB community.

[1] For leading references on VB theories and related ones, see: a) S. Shaik, P. C. Hiberty, A Chemist's Guide to Valence Bond Theory, John Wiley \& Sons Inc., Hoboken, New Jersey, 2008; b) W. Wu, P. Su, S. Shaik, P. C. Hiberty, Chem. Rev. 2011, 111, 7557.

[2] L. Song, J. Song, Y. Mo, W. Wu, J. Comput. Chem. 2009, 30, 399.

[3] Y. Mo, L. Song, Y. Lin, J. Phys. Chem. A 2007, 111, 8291.

[4] Y. Carissan, D. Hagebaum-Reignier, N. Goudard, S. Humbel, J. Phys. Chem. A 2008, 112, 13256.

[5] A previous workshop on Valence Bond and other highly correlated methods, which brought together physicists and chemists, was organized in Coruña as one of the WATOC 2011 satellites, see: http://watoc2011satelliteconferencecoruna.webs.com/. 